\title{
Autoimmune study in toxoplasmosis women
}

\author{
N. N. A'aiz \\ Coll. of Vet. Med./ Univ. \\ of Al-Qadissyha
}

\author{
B. A. Sultan \\ Coll. of Med. Univ. of \\ Kufa
}

S. M. Al-Fatlawi
Al-Sadar teaching
hospital/ Najaf.

\begin{abstract}
The effecting of toxoplasmosis in production of autoantibodies was studied through three markers, anti-nuclear antibody (ANA), anti-neutrophil cytoplasmic antibody (ANCA) and rheumatoid factor (RF).The immunofluorescent technique (IFAT) was used to estimated the ANA and ANCA ,It was found that $9.8 \%$ and $5.5 \%$ of toxoplasmosis patients had ANA and ANCA respectively, but with no significant differences $(\mathrm{P}>0.05)$ when comparing with control group of each one. RF was tested by LAT and revealed that $10 \%$ of both infected women and healthy controls had antibodies against RF with no significant differences $(\mathrm{P}>0.05)$ between them.
\end{abstract}

\section{Introduction}

Several causes may lead to trigger of autoimmune diseases and the infectious agents are one of these important causes, so the relationship between infections and autoimmune disease has been studied extensively over many years and described the association between microbiological infection (bacterial, viral and parasite) and development of autoimmunity $(14,2)$. The identification of microbial peptides that similar to self- tissue by molecular mimicry is a true factor that inducing or promoting autoimmune diseases triggering

\section{Materials and methods}

Serum samples were collected from healthy individuals as a control group and toxoplasmosis women after tested by ELISA (IgG and IgM) test when attended to hospitals in AL-Najaf and ALQadissyha provinces in Iraq, from September 2008 to February 2009.Then these serum samples were subjected to tested with different three markers to identify the presence of auto antibodies, as the following :

1-Anti-nuclear Antibody (ANA), [Hep2 IFAT]

1- Anti- Nuclear Antibody (ANA):

Out of 51 toxoplasmosis cases, only $5(9.8 \%)$ cases showed positive ANA by immunoflourscent technique using HEP-2

\section{Results} $1)$. by certain infections (2).According to these association between the infectious agents and autoimmune triggering ,this study suggests to identify the relationship between $T$. gondii infection and autoimmune response throughout investigate the presence of some auto antibodies which are anti-nuclear antibody (ANA), anti-neutrophil cytoplasmic antibody (ANCA), and rheumatoid factor (RF) in the serum of toxoplasmosis patients.

Fifty one sera from patients of toxoplasmosis and thirteen sera from healthy women were involved in this test.

\section{2-Anti-neutrophil} Antibody, (ANCA), [IFAT]

Thirty six sera from patients of toxoplasmosis and 12 sera from healthy women were involved in this test.

\section{3-Rheumatoid Factor (RF), [LAT]}

Thirty eight sera from patients of toxoplasmosis and 10 sera from healthy women were involved in this test.

substrate, among 13 controls no one $(0 \%)$ was given positive ANA. (Table 1\&Figure 
Table (1): ANA Patterns in Toxoplasmosis and Control.

\begin{tabular}{|c|c|c|c|c|c|}
\hline & No. & positive & $\%$ & negative & $\%$ \\
\hline Toxoplasmosis cases & 51 & 5 & 9.8 & 46 & 90.2 \\
\hline controls & 13 & 0 & 0 & 13 & 100 \\
\hline \multicolumn{6}{|c|}{$\mathrm{P}=0.24$} \\
\hline
\end{tabular}

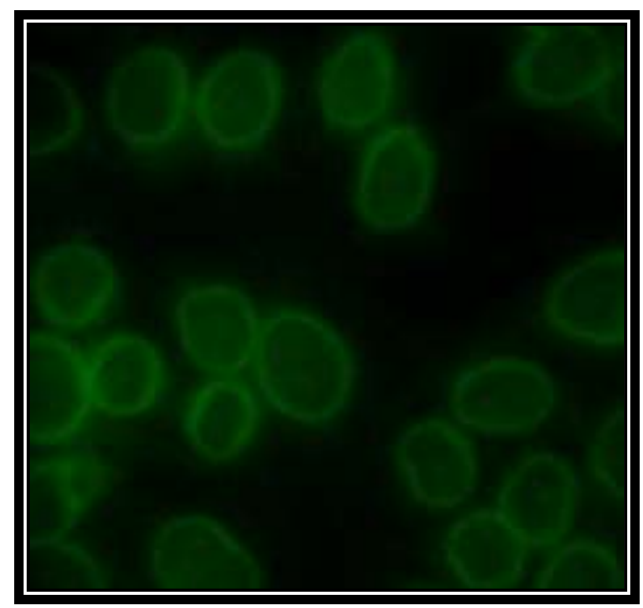

Fig.(1): Positive ANA on HEP-2 Cells (x40)

2-Anti- Neutrophil Cytoplasmic immunoflurscent technique, no positive Antibody (ANCA): ANCA result was detected among the Out of 36 toxoplasmosis cases, Only 2 (5.5\%) patients gave positive ANCA by controls (Table 2\&Figure 2).

Table (2): ANCA Seropositivity in Toxoplasmosis Cases and Controls According to Staining Pattern.

\begin{tabular}{|c|c|c|c|c|c|}
\hline & No. & positive & $\%$ & negative & $\%$ \\
\hline Toxoplasmosis cases & 36 & 2 & 5.5 & 34 & 94.5 \\
\hline controls & 12 & 0 & 0 & 12 & 100 \\
\hline $\mathrm{X}^{2}=0.7 \quad \mathrm{df}=1$ & $\mathrm{P}=0.4$ \\
\hline
\end{tabular}

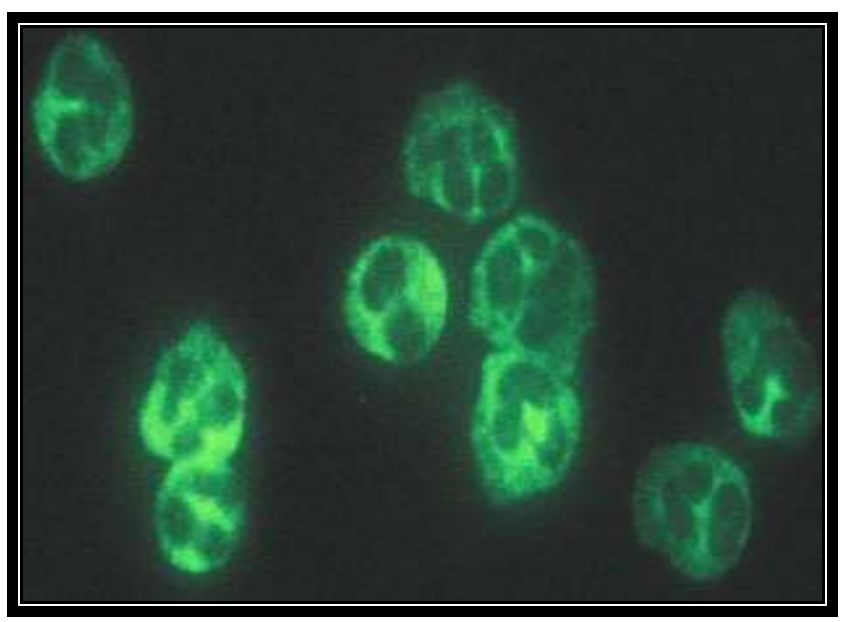

Figure (2):Positive ANCA on Neutrophil Cells(x40) 


\section{3- Rheumatoid Factor (RF) :}

By latex agglutination test, only 4 $(10.5 \%)$ of 38 toxoplasmosis patients revealed positive $\mathrm{RF}$, and one $(10 \%)$ of 10 healthy women gave positive result (Table $3)$.

Table(3): RF Seropositivity in Toxoplasmosis Cases and Controls

\begin{tabular}{|c|c|c|c|c|c|}
\hline & \multicolumn{5}{|c|}{$\mathrm{RF}$} \\
\hline & No. & positive & $\%$ & negative & $\%$ \\
\hline Toxoplasmosis cases & 38 & 4 & 10.5 & 34 & 89.5 \\
\hline controls & 10 & 1 & 10 & 9 & 90 \\
\hline $\mathrm{X}^{2}=0.002 \quad \mathrm{df}=1$ & $\mathrm{P}=0.96$ \\
\hline
\end{tabular}

\section{Discussion}

Infectious agent continues to be among the leading cause of morbidity and mortality worldwide. In addition, they are also implicated in the pathogenesis of in direct consequences such as induction of the autoimmune diseases $(4,6,7)$.In the present study, five markers were examined to determine the autoimmune response in toxoplasmosis patients.

\section{1- Anti- nuclear Antibodies (ANA):}

By immunofluorescent technique using HEP-2 cells as substrate, the study revealed that out of 51 serum samples of toxoplasmosis patients, only 5 (9.8\%) showed positive ANA. The difference of ANA seropositivity was non significant between patients and healthy control groups $(\mathrm{P}>0.05)$. The result revealed a negative correlation between toxoplasmosis and ANA in Iraq, and this result was corresponding the results in Poland and Egypt $(11,12)$ when both confirmed that, the toxoplasmosis do not play essential roles in generating the ANA. High ANA in sporadic case with toxoplasmic pericarditis was reported (9) and suggested that toxoplasmosis may play role in some cases of autoimmune diseases.

\section{2-Anti- neutrophil Cytoplasmic Antibody (ANCA):}

By IFAT, the study revealed that among 36 serum samples of toxoplasmosis patients, $2(5.5 \%)$ showed positive ANCA. This result is more than that obtained by (5) who detected ANCA in 1/44 (2.3\%) of toxoplasmosis patients. In addition ANCA was not detected among 12 healthy women and this in consistent with (5) and (1) they confirmed that, no positive ANCA among 85 and 17 healthy controls respectively.The differences of positive ANCA was not statistically significant between patients group and healthy control group $(\mathrm{P}>0.05)$. ANCA are characteristic marker of small vessels vasculitis and these autoantibodies have the ability to activate neutrophils, monocytes and endothelial cells in vitro (13). Therefore, ANCA may play an important role in the pathogenesis of glomerulonephritis, which represents a rare complication of toxoplasmosis.

\section{3- Rheumatoid factor (RF):}

The seropositivity of RF was estimated for 38 patients with toxoplasmosis by latex agglutination test, and $4(10.5 \%)$ of those patients showed positive results for RF. The difference was not significant between patients group and healthy control group $(\mathrm{P}>0.05)$, the result revealed that there is no correlation between toxoplasmosis and RF in this study. This result was compatible with (12) who mention that no significant relationship between toxoplasmosis and RF. $(3,8,10)$ confirmed that, the elevated of $\mathrm{RF}$ level in some toxoplasmosis patients was due to false positive results and cross reactivity between $T$. gondii and RF occurring in certain tests. 


\section{References}

1. Al-Asady, R. A. (2009). Autoantibody production by Iraqi paediatric patients infected with visceral Leishmaniasis with study of some epidemiological, clinical and diagnostic aspects of the disease. $\mathrm{Ph}$. D. thesis, college of medicine, Baghdad

2. Berlin ,T., Zandman-Goddard,G., Blank,M., Shoenfeld,Y. (2007). Autoantibodies in non autoimmune individuals during infections. Ann N. Y. Acad. Sci., 1108:584-593.

3. Desmontes, G.; Naot, Y. and Remington, J. S. (1981). Immunolobulin MImmunosorbent Agglutination Assay for diagnosis of infectious diseases: Diagnosis of acute, congenital and aquired Toxoplasma infections. J. Clin. Microbiol.; 14(5): 486-491.

4. Gill S.R., Pop M., Deboy R.T.(2006).Metagenomic analysis of human distalgut microbiome. Scince.,312:1355-1359.

5. Hagen, E. C.; Vijver, H.; De-keizer, J. W. ; Kijlstra, A.; Vanes, L. A.; Daha, M. R. and Vander woude, F. J. (1994). Uveitis and antineutrophil cytoplasmic antibodies. Clin. Exp. Immunol.; 95:56-59.

6. Lederberg ,J.(2000).Infectious history .Science;288:287-293.

7. Ley, R.E., Peterson,D.A., and Gordon,J.I..(2006).Ecological and evolutionary forces shaping microbial diversity in the human intestine.Cell.,124 :837-

8. Lin, T.M., Chin-See M. W., Halbert,S.P. and Joseph,J.M.

(1986). An enzyme immunoassay for immunoglobulin $\mathrm{M}$ to Toxoplasma gondii which is not affected by rheumatoid factor or immunoglobulin $\mathrm{G}$ antibodies. J. of Clin. Microbiol., 23(1):77-82 .

9. Lynberg, K.K., Vennervald, B.J., Bygbjerg, I.C.,Hansen,T.M. and Thomsen,O.O.(1992). Toxoplasma pericarditis mimicking systemic lupus erythematosus . Diagnostic and treatment difficulties in one patien. Ann.Med;24(5):337-340.

10.Naot, Y.; Barnett, E. V. and Remington, J. S. (1981). Method for avoiding false-positive results occurring in immunoglobulin $\mathrm{M}$ enzyme- linked sorbent assay due to presence of both rheumatoid factor and antinuclear antibodies. Clin. Microbiol., 14(1):73-78.

11.Pawlowski, T.; Mackiewicz, S. H.; Machowska, L.; Pawlowski, Z.; Van, K. F.; Krup, M. and Shoenfeld, Y. (1991). Toxoplasmosis and systemic lupus erythematosus. Comparative serological studies. Z Rhenmatol., 50(4):204-206.

12. Sarwat ,M. A., Ahmed, A.B., Zamzami,O.M., Fawzy,A.F., and Morsy,T.A.(1993). Toxoplasma gondii in Saudi blood donors a serological study using three tests . J. Egypt soc.parasitol.,23(3):751757.

13. Shankarakumar, V. ,Ghosh,K., Pradhan ,Y.D., Badakere, S.S., AND Mohanty, D. (2005). Immunogenetic association in patients with anti neutrophil cytoplasmic antibodies (ANCA) from Mumbai, Maharashtra. India. J.Autoimmun.,24:227-233.

14.Zandman, G., Berkun, Y., Barzilai, O., Boaz, M., Ram, M., Anaya, J.M., and Shoenfeld, Y. (2008). Neuropsychiatric lupus and infectious triggers. Lupus, 17:380-384 . 


\section{دراسة المناعة الذاتية لا النساء المصابات بلاء المقوسات}

\section{الخلاصة}

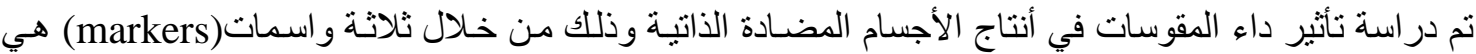

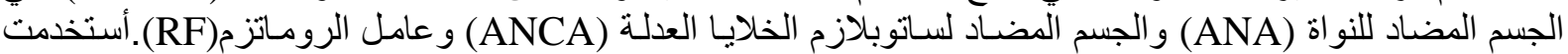

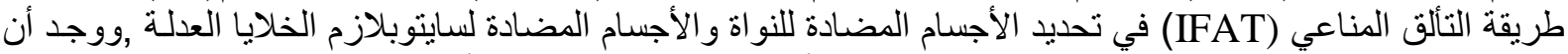

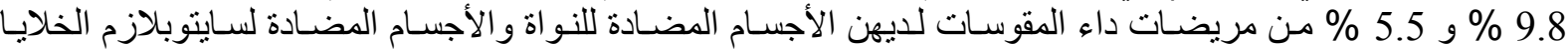

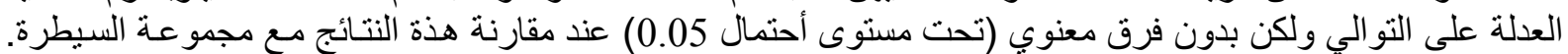

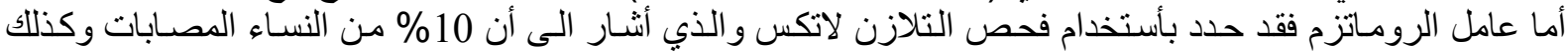

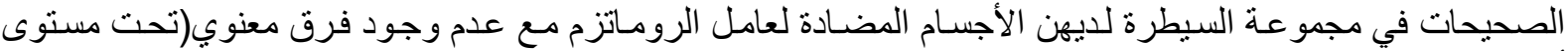
أحتمال 0.05) بين المجمو عتين. 